\title{
The Demonstration of Sexism in Thomas Hardy's Short Stories via Appraisal Analysis
}

\author{
Biook Behnam \\ Department of Foreign Languages, Tabriz Branch, Islamic Azad University, Tabriz, Iran \\ Golpar Bahar \\ Department of Foreign Languages, Tabriz Branch, Islamic Azad University, Tabriz, Iran
}

\begin{abstract}
As Eggins (2005) believes, there are obvious or concealed purposes behind any use of language. So, language evaluation seems essential for realizing theses goals. Recognizing the producers' goals in their discourse will lead to the recognition of their ideology and even ideology of the community they have lived in. The present study considering Appraisal System in some short stories written by Thomas Hardy aims to discover the ways the writer impresses his readers implicitly and makes them accept his hidden ideologies. The Appraisal framework developed by Martin and Rose (2003) is used to analyze the clauses in the stories to manifest writer's point of view towards male and female characters. The study focuses on the way Appraisal resources contribute to the creation of ideologies in the lines of the stories and transfers them to the readers' minds. The results shed the light on the issue and make readers think critically. Being aware of the fact that texts are ideologically loaded, readers' awareness needs to be developed.
\end{abstract}

Index Terms — Systemic Functional Linguistics, appraisal theory, ideology, sexism in language, feminism

\section{INTRODUCTION}

According to Martin and Rose (2003), discourse focuses on the meaning beyond the clause. It means that it is more than a sequence of clauses. Going through one clause to another one leads to the clarification of a text as it is unfolded. It means that discourse is treated as more than an incidental manifestation of social activity; there should be focus on the society as it is constructed through texts, on the constitutive role of meanings in social life. Fairclough (2003) believes that language constructs the world in one way or another according to position or perspective. As Martin and Rose (2003) mention, social contexts play a crucial role in interpreting social discourse at the first step. As sequences of meanings construct texts, social contexts develop. It shows that rarely does Social discourse consists of just single clauses. Interpreting the interaction each text manifests is possible because texts are produced interactively between producers and readers; since each interaction is an instance of the writer's culture and his/her point of view, the text can also be used to interpret aspects of the culture and writer's ideas. According to Mills (1995), discourses are rarely so simple. There are usually multiple facets to them, and multiple positions by different groups. The voices of many groups are to be heard in the texts who are arguing, or being argued for or against, in many subtle ways. The discourse analyses enable these voices to emerge clearly, explicitly, from the patterns of meaning in which they are encoded. Van Dijk (1997) states that discourse play a leading role in the construction and reconstruction of prejudice. The mental models, the social realizations, the perspectives, and ideologies that control people's action and their interaction with others could be acquired by people via books, television programs, news reports in the press, writings, and other forms of public discourse.

Since some attitudes and ideologies in discourses are hidden in the lines, discourse analysts should extract them by implementing some tools. Appraisal is applied as an implemented tool in this research by knowing that according to Martin and White (2005), at the level of discourse semantics, Appraisal is an interpersonal system in the broad field of Systemic Functional Linguistics.

As White (2001) believes:

Appraisal framework, a particular approach to exploring, describing, and explaining the way language is used to evaluate, to adopt stances, to construct textual personas, and to manage interpersonal positionings and relationships. Thus it explores how speakers and writers pass judgements on people generally, other writers/speakers and their utterances, material objects happenings, and states of affairs. It explores how attitudes, judgements and emotive responses are explicitly presented in texts and how they may be more indirectly implied, presupposed or assumed. As well, it explores how the expression of such attitudes and judgements is (pp. 1).

Simply put, the Appraisal analysis seeks to uncover meaning patterns through the systematic analysis of linguistic structures.

Statement of the Problem and Purpose of the Study

As Martin and Rose (2003) mention, writers play a prominent role in the construction of social realities. In their works the reality is not reflected in a neutral mode; however, they help to construct and interpret the reality. Story 
writers exert a prominent influence on public discourse, hence on public opinions which lead to the structuring and maintenance of some ideologies. According to Manan (2001), the language that is used to portray events and people shows selections that are made out of all the available options in the linguistic system and these choices support special ways of noticing and reading. It is obvious that opinions and ideologies have significant social and cultural functions. They play a role in the formation and change of public opinions, in influencing social debates, decision making and other forms of social actions. One of the horrible points in most of the discourses is that a negative view is given to females.

This research tends to investigate how linguistic analysts can use Appraisal analysis in discourse to unpack and reveal implicit and hidden discriminatory ideologies which have been reflected consciously or subconsciously in Thomas Hardy's works. Through the analysis of a set of his short stories, The Withered Arm and The Melancholy Hussar of the German Legion, which exemplify how meanings are constructed and contested in a culture focusing on some issues, readers of his works will be guided to explore the ways in which males and females are introduced and tracked through the texts and also the way they are judged, appreciated and valued. So, by focusing on Appraisals, the researcher tries to shed light on some facts about existing sexism in language and female oppression. By considering Appraisals in the selected stories, the influence of the writer's implicit point of view will be revealed and as a result, the underestimation of language significance will be changed since the awareness of how language contributes to inequality and injustice between the conventional divisions of two genders will be increased.

\section{Theoretical Framework}

Any analysis involving language implies some theory of how language works. Appraisal which evolved within the general theoretical framework of Systemic Functional Linguistics is the framework theory in this thesis. James Martin is one of the greatest practitioners of SFL and his approach (2003) provides useful guidance on how to put this theory into practice. The Appraisal framework has been emerged as a result of research conducted by a group of researchers led by Professor James Martin in the University of Sydney.

In this study the researcher will follow the Appraisal framework of Martin and Rose (2003), and Martin and White (2005) to show how sexism as the writer's ideology has had influence on the Appraisals which have been used in Thomas Hardy's selected short stories and as a result it has been injected to the readers' minds.

\section{Research Question and Hypothesis}

While reading a story, we may think of the world views, social values, culture of the society of the writer, writer's thoughts and ideas and possible convincing impressions of the story. In this research, the researcher will try to answer the following question:

How does Thomas Hardy introduce, judge, and value male and female characters in his short stories by using different Appraisals? To put it simply, how has using special Appraisals for two genders helped Hardy to reflect his sexist prejudice in his works?

It is hypothesized that different Appraisals which have been used in Thomas Hardy's short stories may determine the writer's sexist point of view in oppressing the females.

\section{REVIEW OF THE LITERATURE}

The term 'discourse' has been used differently by various researchers in different cultures. Fairclough (2003) believes that different discourses are different viewpoints in the world that are related to various relations people have in the world based on their place in the society, their social and personal identities, and their social relationships. Not only do Discourses portray the world in a way it is, but also they describe possible worlds that are different from the actual one. According to Yule (1996), discourse analysts focus on the way language users make sense of what they read in texts, the way they understand what speakers mean despite what they say. Discourse, i.e. language use or production or comprehension, is the main kind of social practices influenced by ideologies. In turn, discourses influence and change how we acquire or learn ideologies. In other words, there is a dual link between discourse and ideology (Mills, 1997). We learn ideas especially ideological opinions by having interactions with other group members through reading, listening and speaking. As van Dijk (2003) states, since knowing about the way that ideologies are expressed in discourse and are reproduced in society is needed, particular attention to the discursive dimensions of ideologies is essential.

A systematic resource for stating meaning in context is language. According to Halliday (1985), language is not a fixed defined system or a set of grammatical sentences; language is present in our lives and should be studied in various contexts. It is the study of the ways people exchange meanings by using it. An approach to linguistics developed by Halliday who sees language in a social context is called Systemic Functional Linguistics. Systemic Functional Grammar deals mainly with the choices which are available to users of a language based on their grammatical systems. These choices which are meaningful associate speakers'/writers' meanings with the concrete forms of a language. Basically, SFL as a multi-perspective model has been planned to help analysts to interpret language in use. One of the most important points is the notion of ideational, interpersonal and textual meaning. Ideational meaning is related with construing experience: what's happening, including who's doing what to whom, where, when, why, how. Interpersonal meaning which expresses the way people interact and share their feelings, considers social relations negotiations. How ideational and interpersonal meanings are distributed in waves of semiotics is what textual meaning takes into 
consideration; it means that this type of meaning is concerned with information flow. These three kinds of meaning are called metafunctions (Martin \& White, 2005).

According to Eggins (2005), In order to resist or challenge hidden ideologies in texts, readers need to develop some skills to be able to decode the encoded beliefs; this is the implication of identifying ideology in text. As language does not just represent the realities but actively construct our view of the world, special ways are required to know how language could do that. Based on the explanations above, it is concluded that Appraisal is located as an interpersonal system in SFL. According to White (2001), Appraisal theory is about the linguistic resources by which texts/speakers try to show, discuss and naturalise special inter-subjective and also ideological positions. How the text presents special philosophies or theories about the social orders and considers them as reasonable, essential, or natural will be noticed in examining a text's reading position.

\section{Affect}

As feelings are of two kinds of good or bad, Affect can be positive or negative. Feelings can also be expressed directly or implicitly inferred from the behaviour; so Affect can be expressed directly or implied too. Naming special emotions directly or describing behaviour that also directly expresses emotion means that the writer refers to a mental state in a straight way. However, distinguishing from the physical symptoms is not always easy and the description of unusual behaviour could be interpreted as an indirect sign of emotion. At this time, a bit of psychology is necessary since it will be difficult to be quite sure about the exact meaning of the expressed emotion. More than any other genres, stories involve readers in people's feelings (Martin \& Rose, 2003).

\section{Judgement}

The accepted standard ways of behaving in contexts of proposals are what people should do or not; these norms which are considered as the institutionalization of feeling are called Judgements. Like Affect, positive or negative Judgements of people's character exist and judgements could be done explicitly or implicitly. But unlike Affect, Judgements differ between personal Judgements of admiration or criticism and moral Judgements of praise or condemnation. Judgements are divided into two groups: social esteem and social sanction. Social esteem which is mostly without legal implications involves admiration and criticism; however, social sanction involves praise, and condemnation often with legal implications (Eggins \& Slade, 1977).

\section{Appreciation}

Appreciation which is thought of as the institutionalization of feeling in the context of propositions is the norm about the ways products and performances are valued. Appreciation of things includes attitudes about things. Similar to Affect and Judgement, things are appreciated positively or negatively. Appreciation helps us to turn to meanings that construe evaluations of things that we make and performances we do. Appreciation considers how things are valued (Martin $\&$ Rose, 2003).

\section{Ideology and Discourse}

Ideology refers to a commonsensical systemic set of value system and representations, shared by social groups, often distorted in the service of power, which are mainly produced or reproduced through language. But what is the relation between discourse and ideology? Fairclougch (1989) mentions Language plays a significant role in stabilizing, reproducing and changing ideology. He adds that language always invites the reader to construct a version of reality. Language users with various characteristics in various communicative events may have diverse ideologies, therefore struggles including ideological ones which mainly take place in one through language. On the close relationship between discourse and ideology, Fairclough (1989) adds diverse ideology is seen as a field of both ideology processes, and linguistic processes, and there is a determinate relationship between these two kinds of process; specifically, the linguistic choices that are made in texts can carry ideological meaning. Although the learning of ideologies may be taken place in many social practicing, such as family, school, job, etc. but the primary sources of ideologies acquisition are text and take. Criticizing a language is criticizing the society and their background and ideology since language is closely related to and reflects society and ideology. Language, society and culture change through time. Cameron (1992) says that the most successful situation is when changes in language are along with changes in society, but language and society are so related that changes in language will have caused some changes in society. As Mills (2003) mentions, it is the language of a culture that determines how speakers and readers see the world. It means that language produces our perception of the world. So our thought systems are influenced by the language of the community. Poynton (1989), about the relation between language and culture says that human culture is not random, it is basically patterned.

\section{Sexism}

Sexism is a complex phenomenon, with a number of different possible meanings and causes. In its widest sense as Frye defines the term "sexism" in a way that it can be used to refer to anything that creates, constitutes, promotes, sustains, or explains an unjustifiable distinction between men and women (As cited in Cudd \& Andreasen, 2005).

\section{Sexism in Discourse}

Fowler mentions some ways of sexism. Language is sexist because the ideological paradigm in language considers deviant position for women. Fowler (as cited in Toolan, 1991) discusses about images of women in newspapers. Females are considered as a special group, irrational, dependent to family, powerless and sexual. Language has different position for men and women. Women are considered as a discriminated group, many words refer to women are sexual. 
Schulz (as cited in Thorne \& Henley, 1975) believes that sexism is inherent in language, and dictionaries have stereotypes in definitions they present. Schulz says that Webster Third has given different roles for men and women and also belittled woman.

Title et al. (1976) found that educational achievement tests and college achievement tests are biased against women in language and also in the stereotyped gender roles they give to each sex.

Black and Coward (as cited in Cameron, 1999) locate sexism not in fixed meanings encoded by the linguistic system but in the way meaning is constructed in particular contexts. They observe for instance that it is common to read newspaper reports that say things like "ten survivors, two of them women." but you never read a report saying "ten survivors, two of them men". This has become a regular pattern. So as it is clear, there is a special need for some ideologies to be implemented to make the texts less sexist not to let readers have sexism subconsciously in their mind as a normal view point.

\section{Feminism}

As Goldberg (1999) believes, since nowadays different types of feminism exist, it is difficult to define feminism. However, most feminists have the same idea that women as a whole are subject to personal and institutional discrimination and are behaved oppressively and differently from men. Feminists also believe that societies are organized in a way that they are to the benefit of men rather than women. Mills (1995) defines feminism as a way of changing the social views to make the society less oppressive to women. Some feminists recommend not using "women's right" or even "the equality" in feminism definition; in their idea equality presupposes a standard to which one is equal, in this case the implied standard is men. So they define feminism as a movement for the full humanity of women.

\section{Feminism in Discourse}

Feminists are ultimately in pursuit of a more radical change, the creation of a world in which one gender does not set the standard of human value. Cameron (1992) states feminism as an intellectual approach, seeks to understand how current relations between women and men are constructed - they are constructed, rather than natural - and in the light of this understanding, how they are constructed and how they can be changed. She believes that cultural representations of gender which are demonstrated in literary works, pictures, textbooks, academic articles, and other works are very important in shaping the identities of males and females, their notions of masculinity and femininity, and their opinion about what is usual.

What the researcher would like to capture in this research is the way that the meanings of gender are represented so it would be possible to contest those representations, or reinterpret them. Then it would be obvious how strange is the way gender difference is represented in different cultures, so that perhaps writers might be able to think of ways in which female could be represented differently and more productively. The reader could find out more about the underlying messages of the text. Following systematic patterns and concentrating on particular aspects of texts can tell the reader a great deal more about the text than a simple reading which focuses on the subject-matter of the text alone.

\section{METHODOLOGY}

\section{Materials}

To deal with the hypothetical answer to the research question and to implement the Appraisal framework for analysis, the data pool for analysis includes two short stories by Thomas Hardy, namely: The Withered Arm and The Melancholy Hussar of the German Legion were selected. These stories were selected just based on the existence of two opposite sexes in the stories to let the researcher do the analysis. The selected stories are from Wordsworth Classics, Thomas Hardy, Wessex Tales (1995).

\section{Procedure}

Appraisal that is of attitudinal positioning is focused on in this research. In this system, the subcategories are Affect, which is the resources deployed for construing emotional responses; Judgment, that is used for understanding moral evaluations of manner; and Appreciation, which makes the aesthetic quality of semiotic text/processes and natural phenomena (Martin, 2000). Having selected the material, to achieve the aforementioned purpose of the study, the researcher follows the following procedures for analysing Appraisal in Thomas Hardy's selected short stories which are outlined by Martin and Rose (2003). Each text is broken down into its constituent clauses and each clause is specified numerically separately for two genders. Adopting Halliday's Systemic-Functional Grammar and implementing Appraisal tool, all the Appraisal items are identified and classified according to three subcategories of attitudinal positioning; then for getting an overview of the text as a whole, the results for men and women are tabulated separately.

White (2001) mentions In considering Attitude, the researcher considers the utterances that are indicators of some people, things, conditions, actions, happenings or state of affairs. They are interpreted either positively or negatively. So, the researcher categorizes any utterance which conveys a negative or positive evaluation or which can be interpreted for encouraging the readers to make their own negative or positive assessments. Surely, there are examples of individual words conveying a clear attitudinal meaning. But mainly instead of individual words, word combinations convey the meaning. It is better to consider attitude as feature or property, not individual words. They are complete utterances, the stretches of language which show a complete proposition or proposal. Therefore, in Attitude analysis, the researcher draws the conclusion that attitudinal meanings are better noticed when they are carried by complete propositions not 
individual words although in some cases it is possible to consider individual lexical items. So, the proposition or proposal, or a sequence of interrelated propositions or proposals are analysed in the context of the larger text as the unit of analysis. The researcher works on explicit and implicit Attitude too. For explicit Attitude, overtly evaluative/attitudinal words or combinations of words and phrases which clearly carry a positive or negative sense are studied. In contrast, identifying instances of implicit evaluative/attitudinal wordings in the utterance is not easy. Rather, the audience/respondent interpretation of the happening is more considered. The writer/speaker relies on the reader/listener's evaluation of events and characters.

At the first step, the Affect which deals with the choice of words for showing the positive and negative feelings of two genders will be studied. By referring to a mental state and using words for special emotions or at times by referring to physical emotion and describing manner that directly expresses emotion, feelings could be expressed directly. They could also be expressed implicitly by description of strange and uncommon manner that can be considered as an implicit sign of emotion or by using metaphor. At the second step, the researcher will examine the Jud gment category to clarify the evaluation of males and females based on their behaviour and character which could be admired, criticised, praised, and condemned. At the end, the Appreciation of things related to two genders will be clarified; Appreciation of things includes the writer's Attitudes about two genders' belongings. Like Affect and Judgment, appreciation of things can be done positively or negatively (Martin \& Rose, 2003).

Data Analysis and Discussion

Following (Martin \& Rose, 2003), the researcher is to provide readers with available instruments for discourse analysis in SFL which is called Appraisal. This phase deals with different types of attitudes which are expressed in the selected short stories by Thomas Hardy. The first pair of Tables shows the writer's expression of feelings for both male and female characters. The second pair of Tables will focus on the judgement of characters and the last pair of Tables implies the evaluation of things for two genders.

\section{RESUlts}

\section{Attitude Analysis in The Withered Arm \\ Affect Analysis}

As it was described before, there are some sub-categories in Affect analysis, some of which will be just concentrated upon in this part of the study namely as the positive and negative words. This is to show how the writer consciously or subconsciously has described males and females' feelings in a different way.

TABLE1.

FREQUENCY OF EVALUATIVE WORDS IN AFFECT ANALYSIS

\begin{tabular}{|l|l|l|}
\hline & Positive & Negative \\
\hline Male & $\mathbf{3}$ & $\mathbf{1 2}$ \\
\hline Female & $\mathbf{4}$ & $\mathbf{8 7}$ \\
\hline
\end{tabular}

As it is shown in Table 1, there are 87 negative affects for female characters in the story which is nearly seven times more than the negative affects for male characters. Since the number of affected clauses is not equal for opposite genders, to calculate the number of Appraisal occurring for them may not seem to be a logical way to gain accurate results; therefore, the results have been transformed to percentage forms. The percentage output of Table 2 unveils discriminative attitude of the writer towards genders where he undervalues females by allocating just 4.3 percent of positive Affects for them, while he assigns 20 percent of it for his male characters; as a matter of fact, the female characters take in 80 percent of their Affect as negative.

TABLE2.

PERCENTAge Frequency of Evaluative Words in AFFECT ANALYSis

\begin{tabular}{|l|l|l|}
\hline & Positive & Negative \\
\hline Male & $20 \%$ & $80 \%$ \\
\hline Female & $4.39 \%$ & $95.60 \%$ \\
\hline
\end{tabular}

Providing an illustration will clarify the point much better.

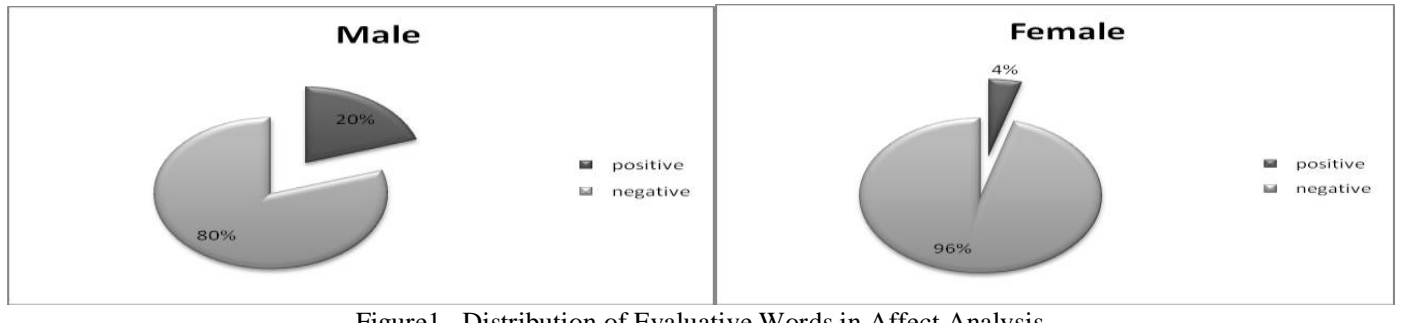

Figure1. Distribution of Evaluative Words in Affect Analysis

\section{Judgement Analysis}


As it has already been mentioned, Judgement is applied to construe people's attitudes to the way others behave and their character. According to Martin and White (2005), social and interpersonal values are judgements that appraise people's normality, capacity, or tenacity; they are put under the branch of Social Esteem. On the other hand, judgements of Social Sanction, which are used to make evaluations about morals, concern ethical or legal matter. Although both Judgements of Social Esteem and Social Sanction are formed by the special cultural and ideological situation in which they appear, the Judgements of Social Esteem have less social weight than Social Sanction. In the story, the analysis shows that the writer's judgement of his male characters is as high as $76.92 \%$ positive and just $23.07 \%$ negative, while his judgement of female characters is only $38.09 \%$ positive but $61.90 \%$ negative (Table 3 ). Yet another fact to prove his discrimination is that he has morally praised his male characters four times more than female characters and amazingly has morally condemned females three and half times more than males. The study of frequency and percentage of evaluative words in judgement analysis of the story can give the reader a clearer idea of this discrimination.

TABLE3.

PERCENTAgE FREQUENCY OF EVALUATIVE WORDS In JUdGEMENT ANALYSIS

\begin{tabular}{|l|l|l|l|l|l|l|}
\hline \multirow{2}{*}{} & \multirow{2}{*}{ Positive } & \multirow{2}{*}{ Negative } & Personal & Moral & Condemn \\
\cline { 4 - 7 } & & & Admire & Criticize & Praise & $\mathbf{7 . 6 9 \%}$ \\
\hline Male & $\mathbf{7 6 . 9 2 \%}$ & $\mathbf{2 3 . 0 7 \%}$ & $\mathbf{3 8 . 4 6 \%}$ & $\mathbf{1 5 . 3 8 \%}$ & $\mathbf{3 8 . 4 6 \%}$ & $\mathbf{2 3 . 8 0 \%}$ \\
\hline Female & $\mathbf{3 8 . 0 9 \%}$ & $\mathbf{6 1 . 9 0 \%}$ & $\mathbf{2 8 . 5 7 \%}$ & $\mathbf{3 8 . 0 9 \%}$ & $\mathbf{9 . 5 2 \%}$ & \\
\hline
\end{tabular}

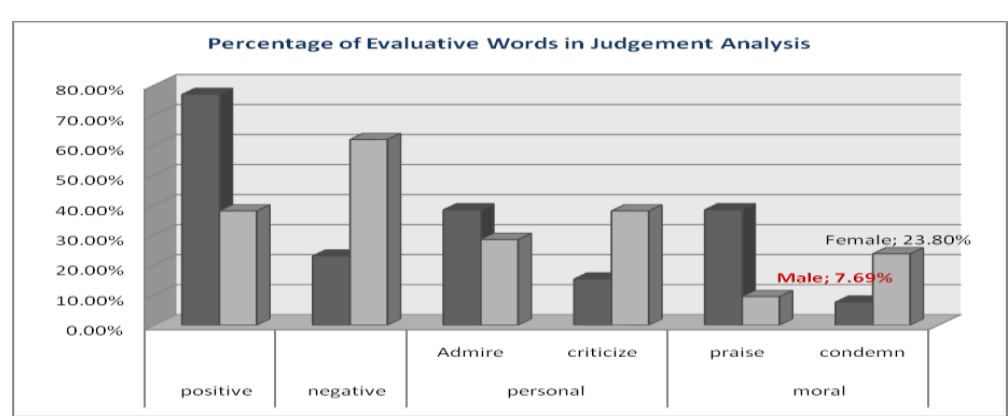

Figure2. Percentage Frequency of Evaluative Words in Judgement Analysis

\section{Appreciation Analysis}

The Appreciation of the things which is associated with male characters helps to give a firm mind to prove the hypothesis of disvaluing females against males. Here the subconscious mind of the writer has been crude enough towards his female characters to assign $100 \%$ percent positive appreciation of his male characters against the minor percentage of $5.55 \%$ for the females. This shocking difference is the bare evidence and proof to conclude the fact which is shown in Table 4.

TABLE4.

PERCENTAge Frequency of Evaluative Words in APPRECIATION ANALYSis

\begin{tabular}{|l|l|l|}
\hline & Positive & Negative \\
\hline Male & $100 \%$ & - \\
\hline Female & $5.55 \%$ & $\mathbf{9 4 . 4 4 \%}$ \\
\hline
\end{tabular}

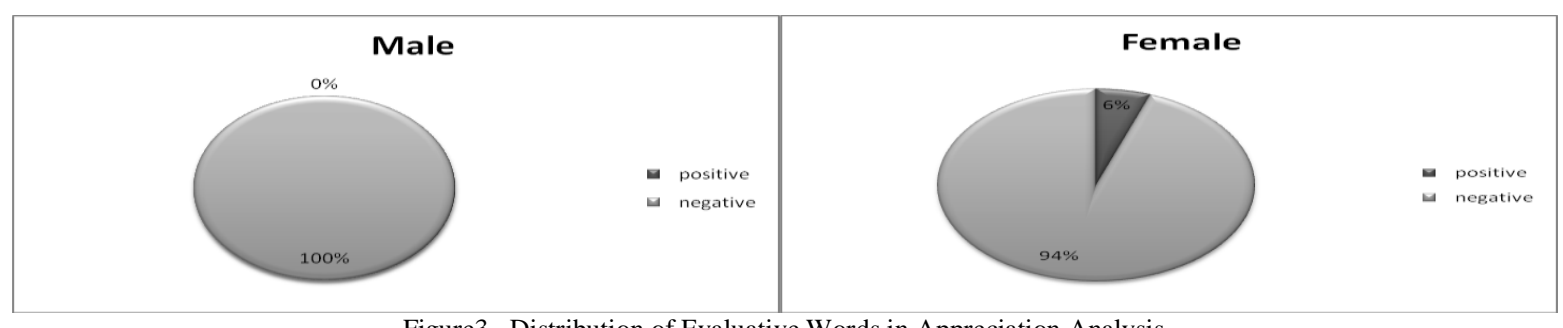

Figure3. Distribution of Evaluative Words in Appreciation Analysis

\section{Attitude Analysis in The Melancholy Hussar of The German Legion}

\section{Affect Analysis}

The results of the Affect analysis are in the same stream with other parts of the study to prove the discrimination. The number of positive Affects for male characters in this story is three times more than the same type of Affects for females, and consequently, the number of negative ones in females is twice male characters.

TABLE5.

PERCENTAGE FREQUENCY OF EVALUATIVE WORDS IN AFFECT ANALYSIS

\begin{tabular}{|l|l|l|}
\hline & Positive & Negative \\
\hline Male & $\mathbf{1 8 . 1 8 \%}$ & $\mathbf{8 1 . 8 1 \%}$ \\
\hline Female & $\mathbf{6 . 6 6 \%}$ & $\mathbf{9 3 . 3 3 \%}$ \\
\hline
\end{tabular}




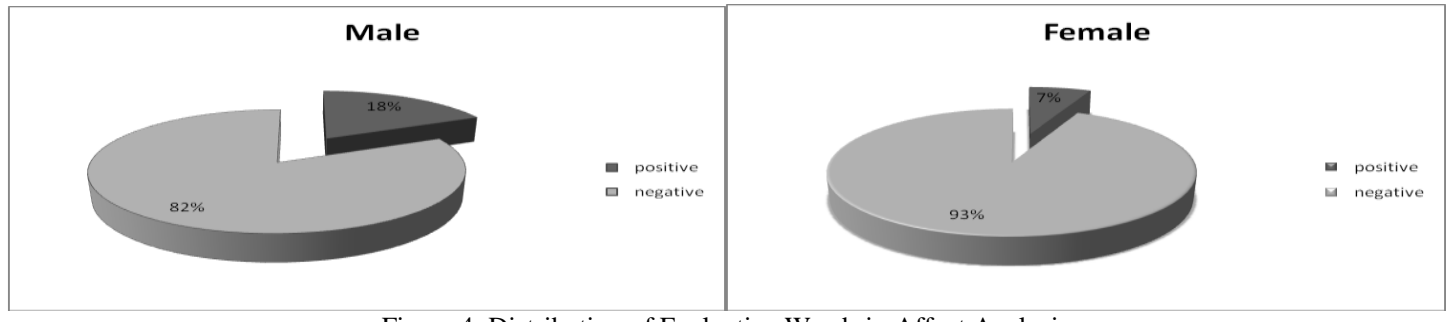

Figure 4. Distribution of Evaluative Words in Affect Analysis

\section{Judgement Analysis}

Judgement analysis results are another outstanding fact screening overwhelming masculine dominance in the story tone. Except for a slight imbalance in personal admiration in favour of female characters, all appreciations and valuation have been guaranteed for male characters. Yet, the so called admiration for female characters is only about four percent more than males, but in case for male characters the difference is so much higher (Table 6). The Figures in the judgement analysis and also in every section of the study speak better to reveal the writer's intention and his inclination towards his male characters, where he constantly disvalues the females.

TABLE6.

PERCENTAGE FREQUENCY OF EVALUATIVE WORDS IN JUDGEMENT ANALYSIS

\begin{tabular}{|l|l|l|l|l|l|l|}
\hline & Positive & Negative & Personal & Moral & Condemn \\
\cline { 3 - 7 } & & & Admire & Criticize & Praise & - \\
\hline Male & $\mathbf{6 6 . 6 6 \%}$ & $\mathbf{1 2 . 5 \%}$ & $\mathbf{2 9 . 1 6 \%}$ & $\mathbf{8 . 3 3 \%}$ & $\mathbf{4 1 . 6 6 \%}$ & $\mathbf{2 2 . 2 2 \%}$ \\
\hline Female & $\mathbf{5 5 . 5 5 \%}$ & $\mathbf{4 4 . 4 4 \%}$ & $\mathbf{3 3 . 3 3 \%}$ & $\mathbf{4 4 . 4 4 \%}$ & $\mathbf{2}$ & - \\
\hline
\end{tabular}

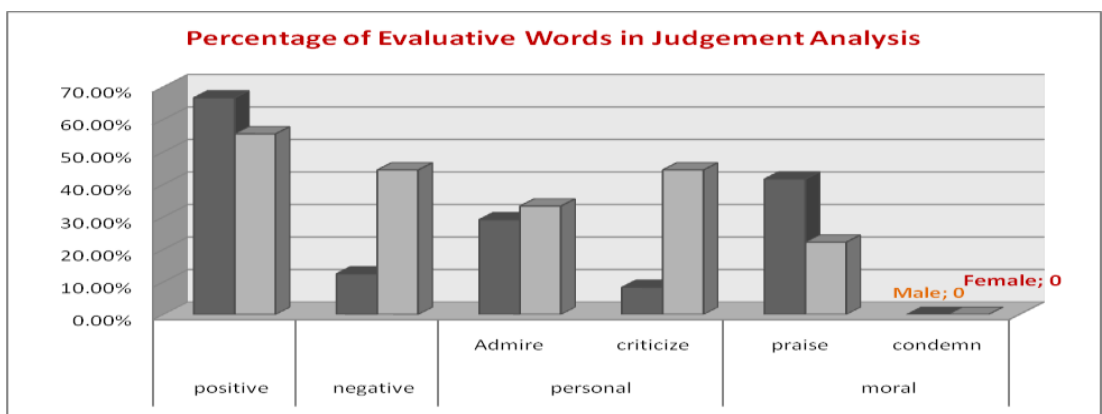

Figure5. Percentage Frequency of Evaluative Words in Judgement Analysis

\section{Appreciation Analysis}

The output of appreciation analysis, again, is in the course with discrimination of the opposite genders imposed by the writer to the whole story. Undermining feminine dignity and establishing splendour and magnificence for masculine force is highlighted by distinguishing positive and negative appreciations for male and female characters, where, once more, male characters are elevated by about 84 percent positive appreciation against humiliating 80 percent negative appreciation for female counterparts. This stream is tightly followed by the writer over and again and his discriminative view is traced throughout the story. Insistently, the writer is going to imply to his reader the superiority of his masculine society over female characters and generalize it to outer and bigger societies.

TABLE7.

PERCENTAGE FREQUENCY OF EVALUATIVE WORDS IN APPRECIATION ANALYSIS

\begin{tabular}{|l|c|c|}
\hline & Positive & Negative \\
\hline Male & $\mathbf{8 3 . 3 3 \%}$ & $\mathbf{1 6 . 6 6 \%}$ \\
\hline Female & $\mathbf{2 0 \%}$ & $\mathbf{8 0 \%}$ \\
\hline
\end{tabular}

Male

Figure6. Distribution of Evaluative Words in Appreciation Analysis

\section{Interpretation and Explanation}

Interpretations are generated through a combination of what is in the text and what is the interpreter's view point. From the point of the interpreter, the evaluative words which have been used by the writer in the selected stories, can determine the writer's different attitudes towards male and female. So the interpretations will be generated based on the 
result of Appraisal system. As the results show, this Appraisal inequality is not simply a random result; the texts seem to be distinctively gendered and show sexist language. Mills (1995) for explaining the sexist language says: "by examining examples of usage such as the sex-specific pronoun use, the misuse of generics, address terms and the negative descriptions of females in a variety of texts, it is hoped to show that language-use can present and perpetuate a particular view of women"(pp. 83). This research reveals the writer's conscious or subconscious intention in the use of constant negative words and phrases to imply to his reader the female gender as an inferior to her male counterpart. This goes to extreme where by continuous application of these negative words, even women will incarnate a negative picture for themselves and their anticipation of themselves will shift in a negative way. As the results indicate, in order to express the feelings and things associated with female characters, the writer has frequently applied negative appreciations. In contrasting ethics and behaviour of the genders, Hardy has weighed the balance for male characters in a great deal, and he has appointed too little positive admiration for female characters for their social deeds. Therefore, it could be concluded that different Appraisals which have been used in Thomas Hardy's short stories determine the writer's sexist point of view in oppressing the females.

One of the effects of using sexist language as Sara Mills (1995) believes is that: "it may cause women to view themselves in a negative or stereotyped way. It may thus have an effect on the expectations women and men have of what women can do" (pp. 95). Some feminists see sexist language as symptomatic of discrimination and propose reformation. There is an alternative to these views, proposed by feminists such as Daly and Spender; they see sexist language as a casual factor in women's oppression (Daly \& Sender, as cited in Mills, 1995). Negative appreciation of female characters in the stories will harmfully affect the women's dignity in the society, for sure. The interrelation of language and society is undeniably taken for granted, and subsequently, the suitable modification in language use will leave its positive feedback in the society. In Robin Lakoff's idea, sexism in language is a symptom of sexism in the community; it means that sexism within the society is reflected by the sexism in language (Lakoff, 1975). They argue that only by changing that wide sexism in the society will any change occur in language. Cameron (1992) believes that language is an extremely important element in the formation of our world-view and the way we think. She mentions that in order to change sexist language it is not enough to reform the language-use of individuals; the change has to be at an institutional level, at the level of what she calls the "gatekeepers of language" although it is a very difficult task. Obviously, such unequal presentation of men and women in the stories will result in destructive superiority and dominance of the male gender. Norman Fairclough states in his book Language and Power that his objective is to enhance consciousness of language and power and especially the ways language helps to the domination of a group of people by others (Fairclough, 1989). Sara Mills agrees with his aim in many ways, since analysis of language can help the reader be aware of ideologies of gender difference which are oppressive.

There are other frequent researches completed on different texts in the field of inequality of opposite genders, and in all of these researches the female gender has been regarded as inferior. Textbooks have been studied by many researches looking for various ways of sexism too. The importance of this work is obvious. Text books like other books, newspaper, journals, story books, etc. must be out of any kinds of racism and sexism.

Sunderland and other lexicographers of The American Heritage School Dictionary through a computer search of five million words available in American children's school books found that school books contain various ways of sexism; the majority of people in text books were male while there are almost equal boys and girls in school. The ratio of " $h e$ " to "she", "him" to "her" and "his" to "hers" was four to one; The number of men were seven times of the number of women and the number of boys were more than twice of the number of girls. Mothers were more than fathers, the ratio of wife to husband was three to one. It means that women are referred through their relation to men and children. It was suggested that the use of masculine pronoun "he" is for the unspecified singular subject but Sunderland's study of pronoun citation shows that out of 940 citation for he , 744 were used to refer to male humans, 128 to male animals, and 36 to persons in male-linked occupations; only 32 used to refer to unspecified singular subject. These figures show that large number of pronoun " $h e$ " does not refer to unspecified person but it is used for males. The reason for these findings is that most of the texts are written about men. Besides invisibility of women, this search shows that different sets of values, expectations, aims and expected lines have been defined for boys and girls. "Masculine" images are activity, strength, etc, while "feminine" images are inactivity and beauty. After reading, "he was the manliest of his sex and she was the loveliest of hers," a child would say that the word comparable to manly was lovely, not womanly. In the sentence, "the men are strong, virile, and graceful and the girl often beauties," we note that girls, not women, are paired with men and that virile is parallel to beautiful. A feminine figure, a feminine voice, and a feminine laugh are no match for masculine prerogatives, masculine egos, and masculine drives (Sunderland, 2006, pp. 136-137).

Nilsen (1977) says that girls' images in most books are dependents and followers. They are shown as "supportive and appreciative" of boys, boys are shown physically larger than girls. On the other hand, books which have more space for boys have better sells than those for girls.

According to what was said above, there is a necessity for language reform; as feminists believe language is not a neutral and transparent means of reality representation. The sexist language clearly reflects sexist social patterns and continuing the existence of sexist social patterns fails the success of language reform (Cameron, 1999).

Different kinds of sexism must be recognized and eliminated. Recognizing sexism available in story books and eliminating them is more important since these books are read by almost all the children and adolescents. By providing 
materials which contain sexism, readers subconsciously accept the sexism and it will affect their ideology. It is like not giving descriptive realities to them. Texts which contain sexism are not descriptive, they are prescriptive. Invisibility and semantic derogation of women and stereotypes contradicts with the population of sexes, their jobs, roles, aims, etc (Mills, 2003).

\section{CONCLUSION}

This research was an attempt to investigate the association of Thomas Hardy's sexist point of view and his choice of descriptive vocabularies such as Appraisals for male and female characters in his selected stories. It was hypothesized that different Appraisals which have been used in Thomas Hardy's short stories may determine the writer's sexist point of view in oppressing the females.

To answer the research question which was: how has using special Appraisals for two genders helped Hardy to reflect his sexist prejudice in his short stories? The Withered Arm and The Melancholy Hussar of the German Legion were selected from the list of Hardy's short stories for analysis. The clauses in the stories containing Appraisals were numerically highlighted for the either gender, after which, they were grouped according to their sub-categories: Affect, Judgement, and Appreciation. The analysis was conducted upon the Appraisal analysis by Martin and Rose (2003); the results indicated the positive relationship between writer's hidden idea and his choice of words in his writings.

Current movements in the study of language and gender are supported by implementing Appraisal analysis in this research. The different expression of two genders through Appraisal analysis show that even though the hidden ideas are not explicitly expressed in the stories, the gendered inequalities are culturally constructed. It is easy to find contexts where these prejudice may exist, since this research has only dealt with a specific type of writing by a single writer. The outcome of the present research reveals that sexism in language is obvious in most of the texts and speeches, one of which is Thomas Hardy's short stories. With regard to the results of the Affect, Judgement, and Appreciation analysis, the research has detected a large number of negative Attitudes for females in the stories. So, the research clarifies negative views towards female characters that cause sexism, which is also generalized to the female gender in the real society. In most of the clauses during the analysis process similar patterns were encountered. This is due to the fact that the writer is already, subconsciously, influenced by this point of view and he is scattering it to the setting of his stories. They are the result of a social process, not a moment's thought. In the final section, the analysis stream results in a conclusion that the use of different Appraisals for describing male and female characters as a policy, subconsciously, makes readers adopt some discriminatory ideologies which lead to injustice in the society. Therefore, linguistic analysis can help understand the way somebody can achieve his/her goals in removing those oppressive ideas, one of which is the sexism in language. Thomas Hardy as one of the great writers has employed the language in an influential way and put together Affect, Judgment, and Appreciation for his male and female characters in a way that his readers, even women, not being aware of his sexist words against female enjoy reading and praise his works. Of course, in this thesis the researcher has just focused on the above-mentioned categories and it is necessary to mention that there are also other kinds of strategies in Appraisal analysis and more research is needed to study those strategies as well.

\section{REFERENCES}

[1] Cameron, D. (1992). Feminism and Linguistic Theory. London: Macmillan.

[2] Cameron, D. (1999). The Feminist Critique of Language. London: Routledge.

[3] Carabine, K. (1995). Thomas Hardy: Wessex Tales. United Kingdom: Wordsworth Classics.

[4] Cudd, A. E., \& Andreasen, R. O. (2005). Feminist Theory: A Philosophical Anthology. Australia: Blackwell Publishing Ltd.

[5] Eggins, S., \& Slade, D. (1977). Analysing Causal Conversation. London: Cassell.

[6] Eggins, S. (2005). Introduction to Systemic Functional Linguistics (2nd ed.). New York: Continuum

[7] Fairclough, N. (1989). Language and Power. New York: Longman.

[8] Fairclough, N. (2003). Analysing Discourse: Textual Analysis for Social Research. London: Routledge.

[9] Goldbeg, S. (1973). The Inevitability of Patriarchy. New York: William Morrow and Company.

[10] Halliday, M. A. K. (1985). An Introduction to Functional Grammar. London: Edward Arnold.

[11] Lakoff, R. (1975). Language and Woman's Place. New York: Harper \& Row.

[12] Manan, S. (2001). Re-reading The Media: A Stylistic Analysis of Malaysian Media Coverage of Anwar and The Reformasi Movement. Asia Pacific Media Educator, 11, 39-54.

[13] Poynton, C. (1989). Language and Gender: Making The Difference. Oxford: Oxford University Press.

[14] Martin, J. R. (2000). Beyond Exchange: Appraisal Systems in English. In S. Hunston \& G. Thompson (Eds.), Evaluation in Text (pp. 142-175). Oxford: Oxford University Press.

[15] Martin, J. R., \& Rose, D. (2003). Working With Discourse. London: Continuum International Publishing Group.

[16] Martin, J. R., \& White, P. R. R. (2005). The Language of Evaluation. New York: Palgrave Macmillan.

[17] Mills, S. (1995). Feminist Stylistics. London: Routledge.

[18] Mills, S. (1997). Discourse. London: Routledge.

[19] Mills, S. (2003). Gender and Politeness. Cambridge: Cambridge University Press.

[20] Nilsen, A. P. (1977). Sexism and Language. Illinois: National Council of Teachers of English.

[21] Sunderland, J. (2006). Language and Gender: An Advanced Resource Book. London: Routledge.

[22] Thorne, B. \& Henley, N. (1975). Language and Sex: Difference and Dominance. Massachusett: Newbury House. 
[23] Tittle, C. K., K. Mc Carthy, \& J. Steckler.(1976). In J. Pottker \& A. Fishel (Eds.), Sex Bias in The Schools. Teaneck: Fairleigh Dickinson University Press.

[24] Toolan, M. (1991). Narrative: A Critical Linguistic Introduction. London: Routledge.

[25] van Dijk, T. A. (1997). Critical Discourse and Racism. Retrieved 2/20/08, from http://www.discourses.org.

[26] van Dijk, T. A. (2003). Ideology and Discourse. A Multidisciplinary Introduction. Retrieved 2/18/08, from http://www.discourses.org.

[27] White, P. (2001). An Introductory Tour Through Appraisal Theory (word processor version). Retrieved 18/2/08, from http://www.grammatics.com/appraisal.

[28] Yule, G. (1996). The Study of Language (2nd ed.). Cambridge: Cambridge University Press.

Biook Behnam is an Associate Professor of Applied Linguistics in Islamic Azad University, Tabriz, Iran. His current research interests cover Discourse Analysis, ELT, and Translation Studies. He is currently the Editor-in-Chief of the Journal of Applied Linguistics, published by IAU, Tabriz Branch.

Golpar Bahar has MA degree in TEFL from Azad university of Tabriz, Iran, (2008) and BA degree in English Language and Literature from Azad University of Tabriz, Iran (2004). She has been teaching as a foreign language teacher in department of foreign Languages, Daneshvaran University, Tabriz, Iran and department of foreign Languages, Azad University of Mahabad, Mahabad, Iran. 